\title{
Magnitude of ocular trauma in a tertiary care hospital of western Nepal
}

\author{
Godar ST, ${ }^{1^{*}}$ Kaini KR, ${ }^{1}$ Amatya $P,{ }^{1}$ Joshi $K,{ }^{1}$ Singh $L^{1}$
}

${ }^{1}$ Department of Ophthalmology, Manipal College of Medical Sciences, Pokhara, Nepal

\begin{abstract}
*Corresponding Author:
Dr. Srijana Thapa Godar, MBBS, MS

Department of Ophthalmology,

Manipal College of Medical Sciences,

Pokhara, Nepal

E mail: drsrijanathapa@yahoo.com
\end{abstract}

\section{Citation}

Godar ST, Kaini KR, Amatya P, Joshi K, Singh L. Magnitude of ocular trauma in a tertiary care hospital of western Nepal. Nepal Journal of Medical Sciences 2013;2(2):140-3.

\section{Background:}

Ocular trauma is an important cause of visual impairment worldwide. Blindness due to ocular trauma was $2.4 \%$ according to Nepal Blindness Survey, $1981 .{ }^{1}$ In Nepal "corneal trauma and ulceration" is the second most common cause of blindness after cataract. In agricultural societies like Nepal, superficial cornea trauma is more common which often leads to rapidly progressing corneal ulceration and visual loss. ${ }^{2}$ Bhaktapur Eye survey showed the prevalence of ocular trauma was $0.7 \% .^{3}$

\begin{abstract}
Background: Ocular injury is one of the major causes of monocular visual impairment and blindness worldwide, with significant socioeconomic impact. The present study was done to establish the incidence and identify the common causes of ocular trauma in a tertiary care hospital of western Nepal.
\end{abstract}

Methods: This is a cross-sectional study, conducted at a teaching hospital in western Nepal from January 2012 to January 2013. All ocular trauma cases attending emergency and eye OPD were included in the study. A complete history and detailed ophthalmological evaluation was done.

Results: Total number of cases was two hundred and nine. The incidence of ocular trauma was $1.74 \%$. Average age of patients was $28.89 \pm 19.06$ years. Maximum patients were from third decade of life and were males $(66.5 \%)$. Majority of ocular trauma occurred in right eye and were sustained at the workplace. Only $2.4 \%$ of patients used protective agents. The cases presented to the hospital within 48 hours of injury were $71.8 \%$. Maximum subjects didn't use any medication before they presented to this hospital. Road traffic accident (RTA) was the commonest cause of ocular trauma followed by wood stick and fall injury.

Conclusion: Males are more prone to ocular trauma. As the commonest cause is RTA and very few patients used protective devices so public awareness about eye health program and strict legislation for the use of protective devices may help to reduce the magnitude of ocular injury.

Keywords: Blindness; corneal laceration; ocular trauma

Prevention and management of ocular trauma requires a good knowledge on the causative agent of trauma, place of trauma, pattern of ocular damage and vulnerable age group and gender. There is paucity of studies on this topic from western region of Nepal. This study aims to study the magnitude of ocular trauma and to identify the factors leading to ocular trauma in Manipal Teaching Hospital, a tertiary care center in western Nepal. This would help to determine the type of intervention needed for further management and methods of prevention in minimizing the impact of serious injuries. 


\section{Methods:}

It is a cross-sectional study, conducted at Manipal Teaching Hospital, a tertiary care center in western part of Nepal from January 2012 to January 2013. All ocular trauma cases attending emergency and eye OPD of this hospital were included in this study. Total numbers of cases were two hundred and nine. An informed consent was taken from patients or their parents in cases of children.

Demographic profiles of all patients like age, sex, occupation, address etc. were recorded. Detailed history of injury was taken to know the time, place, object of injury, history of using protective agent and treatment taken before coming to this hospital. Mechanism of injury was categorized as mechanical, chemical or thermal. Mechanical injury was further classified according to 'Ocular Trauma Classification Group' by Kuhn and Associates into closed globe and open globe injury. ${ }^{4}$ Visual acuity was measured with Snellen's chart, anterior and posterior segments were examined with slit lamp, +90 D lens (Volk Double Aspheric), direct ophthalmoscope and indirect ophthalmoscope. Different findings were recorded as lids and adnexa (laceration, edema, ecchymosis), conjunctiva (hyperemia, haemorrhage, laceration), cornea (foreign body, abrasion, laceration, ulcer), Anterior chamber (hyphema, hypopyon), iris (iridodialysis, sphinter tear, prolapse, uveitis), pupil \{Relative afferent pupillary defect (RAPD)\}, lens (cataract, sublocation, dislocation), vitreous (haemorrhage, detachment), retina (haemorrhage, tear/break, commotio retinae). Intraocular pressure of both eyes was measured by applanation or by schiotz tonometer (whenever possible and whenever required). Relevant investigations like USG, X-ray orbit/ skull, CT scan and MRI were done whenever indicated. All the patients were examined by the ophthalmologist and appropriate intervention was taken (Medical, surgical). Data of each case was entered in a specially designed proforma and the whole data was analyzed using a SPSS program.

\section{Results:}

Out of a total of 12000 cases attended by the department of ophthalmology during January 2012 to January 2013; 209 were cases of ocular trauma. The incidence of ocular trauma in Manipal Teaching Hospital, Pokhara, Nepal was 1.74\%. The average age of patients presenting with ocular trauma was $28.89 \pm 19.06$ years with a range from 2 years to 94 years. Males were predominantly affected $(66.5 \%)$. The patients belonging from rural areas were $51.7 \%$ whereas $48.3 \%$ were from urban background. Right eye was involved more frequently $(46.9 \%)$ than left eye $(36.4 \%)$ and in $16.7 \%$ of cases both eyes were involved. Maximum patients sustained injuries at the working place. Only $2.4 \%$ of total patients used protective agents. $71.8 \%$ of the total cases presented to the hospital within 48 hours. The percentage of patients didn't use any medication were $85.2 \%, 13.9 \%$ used herbal medication, $0.5 \%$ used antibiotic eye drop and $0.5 \%$ used unknown medication before they presented to this hospital. The patients having visual acuity better than $6 / 18$ were $71.3 \%, 15.8 \%$ had $<3 / 60$ whereas $2.4 \%$ had no perception of light (NPL).

Table 1 show that maximum patients were from third decade of life and table 2 show that RTA was the commonest cause of ocular trauma $(14.8 \%)$.

Table 1: Distribution of patients according to the age group

\begin{tabular}{ccc}
\hline Age group (Years) & Frequency & Percent $(\mathbf{\%})$ \\
\hline $\mathbf{0 - 1 0}$ & 39 & 18.7 \\
$\mathbf{1 1 - 2 0}$ & 43 & 20.6 \\
$\mathbf{2 1 - 3 0}$ & 50 & 23.9 \\
$\mathbf{3 1 - 4 0}$ & 23 & 11.0 \\
$\mathbf{4 1 - 5 0}$ & 22 & 10.5 \\
$\mathbf{5 1 - 6 0}$ & 16 & 7.7 \\
$\mathbf{6 1 - 7 0}$ & 12 & 5.7 \\
$\mathbf{7 1 - 8 0}$ & 3 & 1.4 \\
$\mathbf{8 1 - 9 0}$ & 0 & 0.0 \\
$\mathbf{9 1 - 1 0 0}$ & 1 & 0.5 \\
& $\mathbf{2 0 9}$ & $\mathbf{1 0 0}$ \\
\hline
\end{tabular}

Table 2: Distribution of different causes of ocular trauma

\begin{tabular}{lcc}
\hline Cause & Frequency & Percent \\
\hline Oil & 7 & 3.3 \\
Dust & 14 & 6.7 \\
Wood stick & 27 & 12.9 \\
Fist & 11 & 5.3 \\
RTA & 31 & 14.8 \\
Vegetative agent & 19 & 9.1 \\
Stone & 13 & 6.2 \\
C.P hair & 2 & 1.0 \\
Metal & 17 & 8.1 \\
Finger & 5 & 2.4 \\
Fall injury & 26 & 12.4 \\
Blast injury & 4.0 & 1.9 \\
Welding arc & 8 & 3.8 \\
Insect bite & 5 & 2.4 \\
Lightening & 1 & 0.5 \\
Drowning & 2 & 1.0 \\
Animal bite & 5 & 2.4 \\
Plant sap & 4 & 1.9 \\
Glass & 3 & 1.4 \\
Electric burn & 1 & 0.5 \\
Super glue & 2 & 1.0 \\
Vicks & 1 & 0.5 \\
Hanging & 1 & 0.5 \\
\hline
\end{tabular}


Common ocular findings were conjunctival hyperemia followed by eye lid edema and ecchymosis, corneal abrasion, lid laceration, corneal foreign body, corneal laceration etc. (Table 3)

Table 3: Summary of ocular findings

\begin{tabular}{|c|c|c|}
\hline & No. & Percentage \\
\hline \multicolumn{3}{|l|}{ Lids } \\
\hline Laceration & 33 & 15.8 \\
\hline Oedema and ecchymosis & 79 & 37.8 \\
\hline \multicolumn{3}{|l|}{ Conjunctiva } \\
\hline Sub- conjunctival haemorrhage & 51 & 75.6 \\
\hline Laceration & 9 & 4.3 \\
\hline Foreign body & 10 & 4.8 \\
\hline Hyperaemia & 81 & 38.8 \\
\hline \multicolumn{3}{|l|}{ Cornea } \\
\hline Foreign body & 30 & 14.4 \\
\hline Abrasion & 38 & 18.2 \\
\hline Ulcer & 13 & 6.2 \\
\hline Laceration & 18 & 8.6 \\
\hline \multicolumn{3}{|l|}{ Anterior chamber } \\
\hline Hyphaema & 12 & 5.7 \\
\hline hypopyon & 8 & 3.8 \\
\hline \multicolumn{3}{|l|}{ Uvea } \\
\hline Uveitis & 1 & 0.5 \\
\hline Iridodialysis and sphincter tear & 7 & 3.3 \\
\hline Iris prolapse & 13 & 6.2 \\
\hline \multicolumn{3}{|l|}{ Pupil } \\
\hline RAPD & 6 & 2.9 \\
\hline \multicolumn{3}{|l|}{ Lens } \\
\hline Cataract & 5 & 2.4 \\
\hline Dislocation & 16 & 7.7 \\
\hline \multicolumn{3}{|l|}{ Vitreous } \\
\hline Haemorrhage & 2 & 1.0 \\
\hline \multicolumn{3}{|l|}{ Retina } \\
\hline Haemorrhage & 1 & 0.5 \\
\hline Tear/break & 2 & 1.0 \\
\hline Commotio retinae & 3 & 1.4 \\
\hline
\end{tabular}

\section{Discussion:}

Ocular trauma is a major cause of monocular blindness and visual impairment. A total of 209 patients who sustained ocular trauma were included in this study to find out the magnitude of ocular trauma among patients who presented to Manipal Teaching Hospital, Pokhara, Nepal.

The incidence of ocular trauma was $1.74 \%$ which is more than the one as reported by a study done in Nepal Eye
Hospital $(1.6 \%) .^{5}$

The age group more vulnerable to ocular trauma was 2129 years. Our study has similarity with the study done in Dhulikhel which reported that ocular trauma occurred more frequently in 21-30 years of age group. ${ }^{6}$ Similarly D.B Karki also observed that 20-29 years age group was more affected. ${ }^{5}$ This comprises the economically productive age group and ocular injury in this age group results in great economic loss. Increased incidence of ocular injuries among youngs can be explained by their frequent social activity.

In our study $66.5 \%$ were males and $33.5 \%$ were females. This could be because of more attention being paid for the health of males. In Nepal we have male dominating society and males are given much more importance in general. Other reason may be due to the difference in exposure risk between males and females due to different social behavior. Other studies also showed higher incidence of eye injuries in males than in females. ${ }^{5,6}$

This study shows that closed globe injuries occurred more frequently than the open globe injuries. Other studies also have reported closed globe injuries more frequently than open ones..$^{6,7}$

Most common ocular findings documented in this study were conjunctival hyperemia, eye lid edema, ecchymosis, subconjunctival haemorrhage followed by corneal abrasion, lid laceration, corneal foreign body. 6.2\% cases developed corneal ulcer following ocular trauma. Other studies have found corneal abrasion to be the most common finding., ${ }^{3,7}$

We observed that major cause of ocular trauma was RTA followed by wood stick injury and fall injury in our study. However wood stick was found to be most common object of injury in other studies. ${ }^{6,11,12}$

In this study it was observed that out of 209 patients, only 5 patients gave history of wearing protective devices while working. It is believed that with education about use of proper eye protection, $90 \%$ of eye injuries could be prevented. ${ }^{8}$

This study showed majority of ocular injury occurred in workplace $(64.1 \%)$. Studies conducted in other countries like UK, South Korea and Turkey also showed that factory and workplace accidents were more common probably attributable to growing industrialization., ${ }^{7,9}$ But other studies observed that most ocular injuries occurring during household activities. ${ }^{1,2,6}$

$71.8 \%$ of patients in this study presented in to the eye 
specialist within 48 hours after injury, $15.8 \%$ in between 48 hours - 1 week while $12.4 \%$ presented after 1 week duration. Study at Dhulikhel also has reported that 54.5\% patients presented within a day. ${ }^{6}$

This study has observed that ocular trauma occured more frequently in right eye (46.9\%) than in left eye (36.4\%). More involvement of right eye was also noted by other studies. ${ }^{5,10}$

$85.2 \%$ of our patients didn't use any medication, $13.5 \%$ used herbal preparation, $0.5 \%$ used antibiotics eye drop and $0.5 \%$ used unknown medication. This could be due to lack of health education and awareness among patients regarding ocular trauma.

\section{Conclusion:}

Males are more prone to ocular trauma than female and majority of ocular trauma occurred at workplace. RTA is the commonest cause of ocular trauma. Very few patients used protective devices resulting to such a magnitude of monocular impairment so eye health awareness program and strict legislation to use protective devices should be emphasized so that it could help to reduce the occurrence of ocular trauma.

\section{References:}

1. Brilliant LB, Pokhrel RP, Grasset NC, et al. Epidemiology of blindness in Nepal. Bulletin of the World Health Organization 1985;63:375-86.

2. Khatri SK, Lewis AE, Schein OD, et al. The epidemiology of Ocular trauma in rural Nepal. Br J Ophthalmol 2004;88:456-60.

3. Upadhyay MP, Karmacharya P, Koirala S, et al. Bhak- tapur Eye Study: Ocular trauma and antibiotic prophylaxis for the prevention of corneal ulceration in Nepal. Br J Ophthalmol 2001; 85:388-92.

4. Kuhn F, Morris R, Witherspoon D, et al. A standardized classification of ocular trauma. Ophthalmology 1996;103:204-3.

5. Karki DB. Ocular Morbidity due to Trauma. PMJN 2008;8:1-12.

6. Sthapit PR, Marasini S, Khoju U, et al. Ocular Trauma in patients presenting to Dhulikhel Hospital. Kathmandu Univ Med J 2011;33:54-7.

7. Oum BS, Lee JS, Han YS. Clinical features of Ocular Trauma in Emergency Department. Korean J Ophthalmol 2004;18:70-8.

8. Mallika PS, Tan AK, Asok T, et al. Pattern of ocular trauma in Kuching, Malasia. Malaysian Family Physician 2008;3:140-5.

9. Oner A, Kekec Z, Karakucuk S, et al. Ocular trauma in Turkey: A 2-year prospective study. Adv Ther 2006;23:274-80.

10. Thompson CG, Kumar N, Billson FA, et al. The aetiology of perforating ocular injuries in children. Br J Ophthalmol 2002; 86:920-922.

11. Adhikari Rk, Pokhrel H, Chaudhary H, et al. Ocular trauma among children in western Nepal: agents of trauma and visual outcome. Nep J Oph 2010;2:164-5.

12. Malla BK. Structural changes in Ocular trauma and the visual outcome. Kathmandu Univ Med J 2003; 2:113-8. 